\title{
Análise da eficiência de um filtro de pedra porosa desenvolvido para o tratamento preliminar de esgoto doméstico
}

\author{
Analysis of the efficiency of a porous stone filter developed for the preliminary treatment of \\ domestic sewage
}

\author{
T. M. A. Albuquerque*; I. D. H. Sousa; I. R. Almeida; T. P. Souza; L. E. Teixeira; \\ A. K. O. Souza; I. R. Santana \\ Coordenadoria de Engenharia Civil/Laboratório de Saneamento Ambiental, Instituto Federal de Sergipe, 49055-260, \\ Aracaju-Sergipe, Brasil
}

*tatiana.maximo@uol.com.br

(Recebido em 27 de maio de 2017; aceito em 11 de outubro de 2017)

\begin{abstract}
Frente à necessidade de uso racional dos recursos hídricos conforme preconizado na Lei 9433/97, principalmente na região nordeste do Brasil, cuja disponibilidade hídrica é pequena devido à climatologia local, às demandas, além do mau uso dos recursos hídricos que são utilizados como meio de diluição de esgotos, como é o caso de muitos rios das bacias do estado de Sergipe, observa-se que a adoção de medidas que gerencie aumento de oferta e gerenciamento de demanda é essencial. Nesta pesquisa buscou-se analisar a eficiência do uso de uma pedra porosa de filtro, à base de cal, para tratamento preliminar de esgotos domésticos que serão direcionados para fins não potáveis, auxiliando assim na redução de poluentes contidos nos esgotos antes de serem lançados in natura. A análise desta eficiência foi realizada através de testes físicoquímicos como: $\mathrm{DBO}_{5}, \mathrm{DQO}$, turbidez, cor, sólidos gerais e em suspensão, cloretos, salinidade, nitratos, e entre outros relacionados à qualidade da água, baseados na Resolução 357/05 do Conselho Nacional do Meio Ambiente - CONAMA. O tratamento com o filtro de pedra porosa criado apresentou baixo custo, fácil produção e utilização, além de ser bastante eficaz no tratamento preliminar do esgoto.
\end{abstract}

Palavras-chave: águas residuais, reuso, qualidade de água

In view of the necessity of a rational use of water resources as envisaged in Law 9433/97, essentially in the northeastern region of Brazil, in which water availability is reduced due to the local climatology, the demands, and the misuse of the water resources that are used as diluted mechanisms of the sewage, as in the case of many rivers in the Sergipe state basins, it is observed that the adoption of measures that manage increase supply and demand management is essential. The objective of this research was to analyze the efficiency of the use of a porous lime-based filter stone for the preliminary treatment of domestic sewage that will be directed to non-noble purposes; thus, it will help to reduce pollutants contained in the sewage before being launched in natura. The analysis of this efficiency was performed through physical-chemical tests, such as: $\mathrm{BOD}_{5}, \mathrm{COD}$, turbidity, color, general and suspended solids, chlorides, salinity, nitrates and others related to water quality, based on the Resolution 357/05 of the National Council for the Environment - CONAMA. The treatment with the created porous stone filter presented low cost, easy production and use, besides being quite effective in the preliminary treatment of the sewage.

Keywords:wastewater, reuse, water quality

\section{INTRODUÇÃO}

O saneamento ambiental é definido como sendo o meio de promoção da saúde pública e tem como objetivo "alcançar níveis crescentes de salubridade ambiental, compreendendo o abastecimento de água; a coleta, o tratamento e a disposição dos esgotos e dos resíduos sólidos e gasosos e os demais serviços de limpeza urbana; o manejo das águas pluviais urbanas; o controle ambiental de vetores e reservatórios de doenças e a disciplina da ocupação e uso do solo, nas condições que maximizem a promoção e a melhoria das condições de vida nos meios urbano e rural" [1].

Nesse contexto, com o aumento contínuo da população e o intenso crescimento das cidades, problemas relacionados com a coleta, tratamento e a disposição dos esgotos têm gerado uma grande preocupação por parte dos órgãos ambientais. Dentre os inconvenientes que podem ser causados 
pelo lançamento indiscriminado de esgoto nos corpos d água destacam-se: o aumento da matéria orgânica, de componentes tóxicos e metais pesados, de turbidez, de ácidos, da temperatura e alteração da cor [2]. Todas essas alterações afetam a autodepuração do curso d'água, fenômeno vinculado ao restabelecimento do equilíbrio no meio aquático, por mecanismos essencialmente naturais, após as alterações induzidas pelos despejos afluentes [3].

No Brasil, de acordo com dados da Pesquisa Nacional de Saneamento Básico - PNSB 2008, realizada pelo Instituto Brasileiro de Geografia e Estatística (IBGE, 2010), verificou-se que pouco mais da metade dos municípios brasileiros $(55,2 \%)$ de um total de 5564, possuíam serviço apropriado de esgotamento sanitário por rede coletora. Vale ressaltar, que esses dados se referem apenas a existência do serviço no município, sem considerar se o esgoto é tratado ou não, após ser coletado [2].

Hoje, pode-se verificar que várias cidades brasileiras já contam com estações de tratamento de esgoto, porém devido ao crescimento desordenado das cidades e falta de fiscalização (esgoto clandestino), o tratamento não é eficiente e muitas delas correm o risco de ficarem sem mananciais de água apropriada para o abastecimento público ou ainda amargarem sérios problemas de saúde pública [4].

Quanto à legislação ambiental no Brasil, quem estabelece as condições e os padrões de lançamento de efluentes em cursos d'águas é a resolução no 357 do CONAMA (Conselho Nacional do Meio Ambiente), a qual controla o lançamento no meio ambiente de poluentes, proibindo o lançamento em níveis nocivos ou perigosos para os seres humanos e outras formas de vida. De acordo com essa resolução [5], o controle de poluição estará diretamente relacionado com a proteção da saúde, que é garantida com um meio ambiente ecologicamente equilibrado.

O tratamento de esgoto na ETE (Estação de Tratamento de Esgoto) é dividido historicamente, nos níveis preliminar, primário, secundário e terciário. No tratamento preliminar (processo físico), ocorre a eliminação de sólidos grosseiros, de gorduras e areias, utilizando geralmente uma grade e um desarenador. O tratamento primário (processo físico) é onde ocorre a remoção dos sólidos sedimentais e redução de parcela da matéria orgânica. No nível secundário (processo biológico) ocorre remoção da matéria orgânica através do ataque com micro-organismos. Por fim, no nível terciário (processo químico e opcional) é utilizado para a retirada de nutrientes, patogênicos, metais pesados e entre outros.

Dentro desse contexto, essa pesquisa visou o desenvolvimento de um filtro de pedra porosa e a avaliação da eficiência da mesma através de uma análise comparativa dos parâmetros físicoquímicos obtidos para amostras de esgoto in natura e para amostras filtradas utilizando o filtro desenvolvimento com o objetivo de auxiliar no tratamento do esgoto doméstico na fase preliminar e assim diminuir custos nas fases posteriores do tratamento.

\section{MATERIAL E MÉTODOS}

A metodologia de trabalho utilizada foi dividida em cinco etapas:

$\left.1^{a}\right)$ Desenvolvimento do filtro de pedra porosa utilizando os seguintes materiais: areia, cal e água

A dosagem dos materiais para a composição da pedra foi realizada empiricamente, de forma com que os componentes atingissem um ponto de umidade possível para coesão e permitissem que a mesma apresentasse vazios. Buscou-se uma relação quantidade de poros e resistência, na qual os poros eram responsáveis pela percolação da água efetuado no processo de filtragem, e a resistência característica da pedra, responsável por garantir o manuseio e suportar uma determinada coluna de água.

$\left.2^{a}\right)$ Coleta da amostra de esgoto doméstico bruto

A coleta foi feita em um canal de águas pluviais que recebe também a contribuição de esgotos domésticos proveniente de casas próximas a ele. O ponto de coleta foi no cruzamento entre as ruas Alan Kardec e Estância, nas proximidades do Instituto Federal de Sergipe no bairro Getúlio Vargas em Aracaju-SE. Foram coletados 4 litros de amostra de esgoto, para análises de amostras brutas e filtradas. 
$3^{a}$ ) Filtragem da amostra de esgoto doméstico coletado para análise da mesma e assim verificar se houve redução das impurezas no esgoto

Nesta etapa do trabalho foram realizadas filtragens das amostras brutas (Figura 1), fazendo o uso das pedras desenvolvidas na pesquisa. Depois de filtradas as amostras, foram realizadas as análises físico-químicas e microbiológicas.

$4^{\text {a }}$ ) Realização das análises físico-químicas e microbiológicas

Foram realizadas no projeto as seguintes análises físico-químicas e microbiológicas das amostras do esgoto coletado e filtrado: Cor aparente, Cor verdadeira, resíduos sedimentáveis, DQO, $\mathrm{pH}$, cloretos, nitrogênio amoniacal, condutividade elétrica, turbidez, salinidade, sólidos totais, sólidos totais dissolvidos e sólidos totais voláteis, sólidos totais fixos, coliformes totais, e $\mathrm{DBO}_{5}$, segundo Standard Methods.

As análises de: $\mathrm{pH}$, condutividade elétrica, turbidez, sólidos totais dissolvidos e salinidade foram feitas de acordo com a sonda multiparâmetro (Horiba U52-G).

As análises escolhidas para a realização desse projeto foram as disponiveis no laboratório da instituição de ensino em questão. Tendo em vista que o filtro desenvolvido visava apenas o tratamento preliminar, não haviam normas orientativas para apenas essa etapa do tratamento de efluentes.

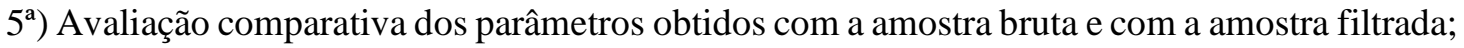

Após realização das análises foi feita uma análise comparativa entre os resultados obtidos das amostras brutas e filtradas do esgoto doméstico, de forma a observar quais efeitos da filtração, através das pedras, poderiam causar na qualidade das águas, observada através das análises físicoquímicas e microbiológicas realizadas nas mesmas.

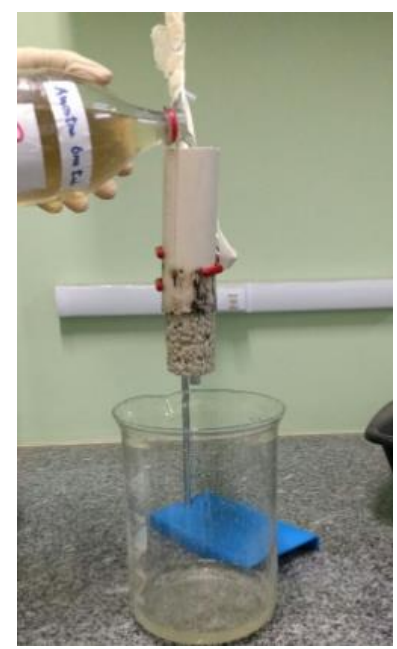

Figura 1: Filtragem da amostra de esgoto bruto coletado utilizando o filtro de pedra porosa criado. Fonte: Os autores (2017)

\section{RESULTADOS E DISCUSSÃO}

Após a realização das análises físico-químicas e microbiológicas foram obtidos os resultados conforme mostra a Tabela 1, onde tem-se os dados obtidos para os parâmetros estudados para as amostras de esgoto bruto e de esgoto filtrado no filtro de pedra porosa elaborado, além disso, há uma análise comparativa de redução ou aumento dos parâmetros selecionados para as duas amostras. 
Tabela 1: Resultados das análises realizadas nas amostras de esgoto bruta e de esgoto filtrado

\begin{tabular}{|c|c|c|c|}
\hline Parâmetros analisados & $\begin{array}{c}\text { Amostra } \\
\text { bruta }\end{array}$ & $\begin{array}{l}\text { Amostra } \\
\text { filtrada }\end{array}$ & $\begin{array}{c}\text { Redução (-) ou } \\
\text { Aumento (+) } \\
\%\end{array}$ \\
\hline Cor aparente (uC) & 121,75 & 88,5 & $-27,31$ \\
\hline Cor verdadeira (uC) & 34,4 & 29,4 & $-14,53$ \\
\hline DQO $(\mathrm{mg} / \mathrm{L})$ & 125,14 & 73,39 & $-41,35$ \\
\hline $\begin{array}{c}\text { Resíduos sedimentáveis em } \\
\text { águas (ml/L) }\end{array}$ & 15 & 0,1 & $-99,33$ \\
\hline pH & 7,216 & 8,256 & $+14,41$ \\
\hline Cloretos $(\mathrm{mg} / \mathrm{L})$ & 78,261 & 77,735 & $-0,67$ \\
\hline Nitrogênio amoniacal (mg/L) & 5,712 & 2,464 & $-56,86$ \\
\hline Condutividade $(\mu \mathrm{S} / \mathrm{cm})$ & 0,3864 & 0,4080 & $+5,59$ \\
\hline Turbidez (NTU) & 47,344 & 10,620 & $-77,57$ \\
\hline Salinidade (ppt) & 0,02 & 0,02 & 0 \\
\hline $\begin{array}{l}\text { Sólidos Totais Dissolvidos } \\
(\mathrm{mg} / \mathrm{L})\end{array}$ & 0,2512 & 0,2650 & $+5,49$ \\
\hline Sólidos Totais (ST) (mg/L) & 800 & 1600 & +100 \\
\hline $\begin{array}{c}\text { Sólidos Totais Voláteis (STV) } \\
(\mathrm{mg} / \mathrm{L})\end{array}$ & 600 & 1000 & $+66,67$ \\
\hline $\begin{array}{c}\text { Sólidos Totais Fixos (STF) } \\
(\mathrm{mg} / \mathrm{L})\end{array}$ & 200 & 600 & +200 \\
\hline $\mathrm{DBO}_{5}(\mathrm{mg} / \mathrm{L})$ & 112,626 & 66 & $-41,39$ \\
\hline
\end{tabular}

De acordo com os resultados apresentados na Tabela 1, pode-se observar que as maiores reduções ou eficiências da pedra foram identificadas nas análises de: Cor aparente e verdadeira, $\mathrm{DQO}, \mathrm{DBO}_{5}$, resíduos sedimentáveis em água, nitrogênio amoniacal e turbidez.

Com relação às outras análises, os parâmetros praticamente não se alteraram, com reduções abaixo dos $10 \%$, como a condutividade, os cloretos e a salinidade. $\mathrm{O} \mathrm{pH}$ teve um aumento esperado devido a composição da pedra ser com cal.

A série de sólidos teve um aumento, recorrente de dois fatores, o primeiro devido a dissolução da cal na água, o segundo foi que no processo de filtragem ocorreu o desprendimento de partículas de cal e areia da pedra. Este desprendimento ocorreu devido ao pouco tempo de cura da cal pois após testes realizados e consultas na literatura foi constatado que é necessário pelo menos um ano de cura da cal para o ganho de resistência adequada. A escolha desse aglomerante (cal) se deu através de testes onde foi verificada a formação de muitos poros, e a verificação de uma obtenção de resistência necessária para que se pudesse manusear o meio filtrante, dessa forma a quantidade dos materiais precisavam estar bem ajustados com relação ao traço desenvolvido, a fim de se obter um protótipo filtrante capaz de fazer com que as águas residuais pudessem percolar e assim facilitar o processo de filtração desejado.

\section{CONCLUSÃO}

Com os resultados obtidos com a utilização do filtro de pedra porosa criada concluiu-se que:

1) $\mathrm{O}$ filtro de pedra porosa à base de cal e areia apresentou uma relativa eficiência no tratamento da amostra de esgoto coletado, conforme mostrado nos parâmetros obtidos.

2) A adoção do filtro criado no tratamento de águas residuais poderá ser utilizada no futuro como uma técnica complementar para auxiliar no tratamento preliminar de esgoto contribuindo para as etapas do tratamento convencional do esgoto para o posterior lançamento nos cursos d'águas ajudando na sua autodepuração. Questão bastante relevante de ser discutida, em vista, o lançamento indiscriminado de efluentes fora das recomendações do CONAMA, que podem vir em 
um futuro bastante próximo gerar a falta de mananciais com águas com índices de potabilidade adequada para o consumo humano.

3) O tratamento do esgoto utilizando o filtro de pedra porosa criada apresentou baixo custo, fácil produção e utilização, além de ser bastante eficaz no tratamento preliminar do esgoto (eliminação dos sólidos grosseiros) e influenciou no tratamento primário (com a redução dos sólidos sedimentáveis, algo não esperado).

\section{AGRADECIMENTOS}

Ao Instituto Federal de Sergipe (IFS), que por meio dos convênios PIBIC/FAPITEC-SE, PIBIC/CNPq e PIBITI/FAPITEC-SE, concederam-nos bolsas para execução deste projeto de pesquisa. À FAPITEC/SE e ao CNPq pelo apoio financeiro dado para o desenvolvimento da pesquisa em destaque.

\section{REFERÊNCIAS BIBLIOGRÁFICAS}

1. Brasil. Ministério das Cidades. Organização Pan-Americana da Saúde (OPAS). Política e plano municipal de Saneamento ambiental: experiências e recomendações [Internet]. Brasília, DF; 2005. [acesso em 2017 jan. 20]. Disponível em: http://bvsms.saude.gov.br/bvs/publicacoes/politica_plano_municipal_saneamento.pdf

2. Achaval LS. Desenvolvimento e avaliação de um protótipo de estação compacta para o tratamento de esgotos em unidades residenciais unifamiliares [dissertação]. Brasília (DF): Universidade de Brasília; 2014. 173 p.

3. Von Sperling M. Princípios do tratamento biológico de águas residuárias: Princípios básicos do tratamento de esgotos. v. 2, $8^{\mathrm{a}}$ ed., Belo Horizonte: DESA-UFMG, 2011. 211p.

4. Brasil. Presidência da República. Casa Civil. Lei Federal $n^{\circ}$ 9.433, de 8 de janeiro de 1997.Institui a Política Nacional de Recursos Hídricos, cria o Sistema Nacional de Gerenciamento de Recursos Hídricos, regulamenta o inciso XIX do art. 21 da Constituição Federal, e altera o art. $1^{\circ}$ da Lei n ${ }^{\circ} 8.001$, de 13 de março de 1990, que modificou a Lei no 7.990, de 28 de dezembro de 1989 [Internet]. Brasília, DF; 1998. [acesso em 2017 jan. 30]. Disponível em: http://www.planalto.gov.br/ccivil_03/LEIS/L9433.htm

5. Brasil. Ministério do Meio Ambiente. Conselho Nacional do Meio Ambiente (CONAMA). Resolução $n^{\circ}$ 357, de 17 de março de 2005. Dispõe sobre a classificação dos corpos de água e diretrizes ambientais para o seu enquadramento, bem como estabelece as condições e padrões de lançamento de efluentes, e dá outras providências. Alterado pela Resolução CONAMA 397/2008 [Internet]. Brasília, DF; 2008. [acesso em 2017 jan. 30]. Disponível em: http://www.mma.gov.br/conama 